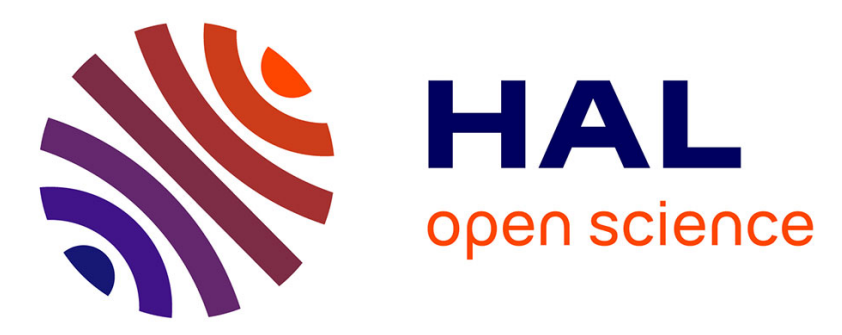

\title{
Chronic sciatic nerve injury impairs the local cutaneous neurovascular interaction in rats
}

Julien Pelletier, Bérengère Fromy, Gérard Morel, Yves Roquelaure, Jean-Louis Saumet, Dominique Sigaudo-Roussel

\section{- To cite this version:}

Julien Pelletier, Bérengère Fromy, Gérard Morel, Yves Roquelaure, Jean-Louis Saumet, et al.. Chronic sciatic nerve injury impairs the local cutaneous neurovascular interaction in rats. Pain, 2012, 153 (1), pp.149-157. 10.1016/j.pain.2011.10.001 . hal-03389871

\section{HAL Id: hal-03389871 \\ https://univ-angers.hal.science/hal-03389871}

Submitted on 21 Oct 2021

HAL is a multi-disciplinary open access archive for the deposit and dissemination of scientific research documents, whether they are published or not. The documents may come from teaching and research institutions in France or abroad, or from public or private research centers.
L'archive ouverte pluridisciplinaire HAL, est destinée au dépôt et à la diffusion de documents scientifiques de niveau recherche, publiés ou non, émanant des établissements d'enseignement et de recherche français ou étrangers, des laboratoires publics ou privés. 


\title{
Chronic sciatic nerve injury impairs the local cutaneous neurovascular interaction in rats
}

\author{
Julien Pelletier ${ }^{\mathrm{a}, \mathrm{b}}$, Bérengère Fromy ${ }^{\mathrm{a}, \mathrm{b}}$, Gérard Morel $^{\mathrm{c}}$, Yves Roquelaure ${ }^{\mathrm{d}}$, Jean Louis Saumet ${ }^{\mathrm{a}, \mathrm{b}}$, \\ Dominique Sigaudo-Roussel ${ }^{\mathrm{a}, \mathrm{b}, *}$ \\ a Institut de biologie et chimie des protéines - FRE CNRS 3310, 69367 Lyon, France \\ ${ }^{\mathrm{b}}$ University of Lyon 1, 69367 Lyon, France \\ ' UMR INSERM 1052 - CNRS 5286, 69008 Lyon, France \\ ${ }^{\mathrm{d}}$ Laboratory of Ergonomics and Epidemiology in Health at Work, University of Angers, University Hospital, 49933 Angers, France
}

Sponsorships or competing interests that may be relevant to content are disclosed at the end of this article.

\section{A R T I C L E I N F O}

\section{Article history:}

Received 12 April 2011

Received in revised form 23 September

2011

Accepted 3 October 2011

\section{Keywords:}

Chronic nerve compression

Small nerve fibers

Large nerve fibers

Neurovascular interaction

Vasodilation

Skin

\begin{abstract}
A B S T R A C T
Most studies of chronic nerve compression focus on large nerve function in painful conditions, and only few studies have assessed potential changes in the function of small nerve fibers during chronic nerve compression and recovery from compression. Cutaneous pressure-induced vasodilation is a neurovascular phenomenon that relies on small neuropeptidergic fibers controlling the cutaneous microvasculature. We aimed to characterize potential changes in function of these small fibers and/or in cutaneous microvascular function following short-term (1-month) and long-term (6-month) nerve compression and after release of compression (ie, potential recovery of function). A compressive tube was left on one sciatic nerve for 1 or 6 months and then removed for 1-month recovery in Wistar rats. Cutaneous vasodilator responses were measured by laser Doppler flowmetry in hind limb skin innervated by the injured nerve to assess neurovascular function. Nociceptive thermal and low mechanical thresholds were evaluated to assess small and large nerve fiber functions, respectively. Pressure-induced vasodilation was impaired following nerve compression and restored following nerve release; both impairment and restoration were strongly related to duration of compression. Small and large nerve fiber functions were less closely related to duration of compression. Our data therefore suggest that cutaneous pressure-induced vasodilation provides a non-invasive and mechanistic test of neurovascular function that gives direct information regarding extent and severity of damage during chronic nerve compression and recovery, and may ultimately provide a clinically useful tool in the evaluation of nerve injury such as carpal tunnel syndrome.
\end{abstract}

(c) 2011 International Association for the Study of Pain. Published by Elsevier B.V. All rights reserved.

\section{Introduction}

Carpal tunnel syndrome (CTS) is a prevalent condition that affects millions of individuals, causing altered sensation and thenar atrophy. Both ischemic and mechanical factors are involved in the development of compression neuropathy [16] and lead to injury of the axon that can be detected by neurophysiological testing [57]. Diagnosis and clinical studies have focused on large myelinated nerve function because patients affected by CTS mainly complain of motor disorders [57]. Moreover, the longer the disease lasts, the greater the neuropathic pain caused by nociceptive fiber damage [51]. Although surgery can relieve nerve pressure in these

\footnotetext{
* Corresponding author. Address: IBCP-FRE CNRS 3310, 7 passage du vercors, 69 367 Lyon, cedex 07, France. Tel.: +33 478778 662; fax: +33 478778739 .

E-mail address: dominique.sigaudo@recherche.univ-lyon1.fr(D. Sigaudo-Roussel).
}

patients, the nervous atrophy is often irreversible, suggesting that diagnosis and treatment are made too late.

Previous experimental studies have shown that chronic nerve injury induced a neural lesion directly attributable to local causes, including disturbances to nerve vascular supply [18], axonal transport mechanisms [41], degeneration/regeneration of myelin sheaths [48], axonal damage [18], and/or connective tissue changes such as endoneurial edema [45]. These alterations were restricted to the area close to the nerve compression at 1 month, whereas at 8 months, damage was evident throughout the nerve [18].

Some experimental immunohistological studies looking at the morphological and phenotypic changes of small and large nerve fibers report discrepant findings $[4,22,23,40]$ probably related to the use of different models of nerve injury and techniques used $[24,38,60,61]$. Regarding the small nerve fibers, calcitonin generelated peptide (CGRP) may be decreased in dorsal root ganglion (DRG) neurons during chronic nerve injury [61], but was also 
reported to be upregulated locally at the nerve injury site, presumably to contribute to small nerve fiber regeneration [50]. Thus, Arendt-Nielsen [1] suggested that small fibers were affected in CTS, but few studies have assessed functional consequences of damage to small cutaneous nerves [46,52,53].

We reported a novel relationship between neural mechanosensitivity and cutaneous vasodilation, referred to as pressure-induced vasodilation (PIV), existing in humans [10] and rats [12]. When external pressure is applied to healthy skin, the cutaneous microarteries vasodilate, delaying the occurrence of ischemia and protecting against damage due to pressure load. PIV involves sensing by capsaicin-sensitive nerve fibers $[10,12]$, releasing neuropeptides, mainly CGRP. These neuropeptides act at the endothelial level to synthesize and release endothelial factors, mainly nitric oxide, inducing smooth muscle relaxation [12]. Therefore, PIV requires intact function of both small unmyelinated $C$ fibers and the endothelium, providing the opportunity to test in vivo small neuropeptidergic fiber function at the cutaneous microvascular area innervated by the injured nerve.

In the present study, we aimed to characterize the incidence of short-term and long-term chronic nerve compression (CNC), as well as the efficacy of nerve release on PIV in the hind limb skin innervated by the injured sciatic nerve. In addition, we performed behavioral tests to assess small and large fiber function and also evaluated endothelial function, because PIV is endothelium dependent $[12,14]$. In this study, we used a CNC [20] to focus on the direct effects of compression without eliciting chronic nociception triggering other mechanisms.

\section{Materials and Methods}

\subsection{Animals}

Adult male Wistar rats weighing between 250 and $275 \mathrm{~g}$ (Janvier, Lyon, France) were kept on a 12/12-hour light/dark cycle with food and water available ad libitum. The present investigation was performed in accordance with the guiding principles in the care and use of animals (Comité Régional d'éthique animale du CNRS de la région Rhône-Alpes, $n^{\circ} 0241$ ).

\subsection{Surgical procedures}

All animals were anesthetized with thiopental sodium (Nesdonal, Merial, France) at a dose of $50 \mathrm{mg} / \mathrm{kg}$. The common branch of the right sciatic nerve was exposed dorsally through a glutealsplitting approach. An 8-mm Silastic tube (246.025 Microflex, Vygon, Ecouen, France) with an internal diameter of $1 \mathrm{~mm}$ and an outer diameter of $2 \mathrm{~mm}$ split-section polyethylene tubing was placed around the right sciatic nerve and left for 1 month ( $\mathrm{C} 1=1$-month $\mathrm{CNC}$ group) or 6 months ( $\mathrm{C} 6=6$-month $\mathrm{CNC}$ group). After 1- or 6-month CNC, the Silastic tube was carefully removed to release the compression and animals were left for 1 month to recover (R1C1 $=1$-month CNC release group after 1 month of CNC; $\mathrm{R} 1 \mathrm{C6}=1$-month $\mathrm{CNC}$ release group after 6 months of $\mathrm{CNC}$ ).

\subsection{Microvascular experiments}

To evaluate cutaneous microvascular function on the hind limb of the rats, a total of three experiments were conducted in each group: (1) the microvascular response to local pressure application (ie, PIV), (2) the endothelium-dependent vasodilation in response to acetylcholine ( $\mathrm{ACh}$ ), and (3) the endothelium-independent vasodilation in response to sodium nitroprusside (SNP).

A pharmacological study was performed to examine the involvement of CGRP and VPAC1/VPAC2 receptors in PIV. The antagonist CGRP8-37 (PolyPeptide Group, Strasbourg, France) was injected intravenously $(100 \mu \mathrm{g} / \mathrm{kg}) 10$ minutes before the onset of local pressure application. To investigate the involvement of VPAC1/VPAC2 receptors in PIV, the antagonist $\left[D-p-C l-P h e^{6}\right.$, Leu $\left.^{17}\right]$-VIP (SC923, PolyPeptide Group) was infused intravenously $(3 \mu \mathrm{g} / \mathrm{kg} / \mathrm{min})$ 15 minutes before the onset of the local pressure application and continued throughout the experiment. To examine cyclooxygenase (COX) involvement in the ACh-mediated vasodilation, the COX inhibitor aspirin (Sigma-Aldrich, Saint Quentin Fallavier, France) was injected intravenously ( $50 \mathrm{mg} / \mathrm{kg}$ ) 30 minutes before the iontophoretic delivery of ACh.

\subsubsection{General protocol for cutaneous microvascular experiments}

Hair from the back and hind limbs of the animals was removed with a depilatory lotion to present a hairless area for skin blood flow measurements, local pressure application, and iontophoretic delivery. This was performed 1 day before the experiments to prevent skin irritation during the experiment from confounding the results. For the microvascular experiments, animals were anesthetized by intraperitoneal injection of thiopental sodium $(50 \mathrm{mg} / \mathrm{kg}$, Nesdonal, Merial, France). The level of anesthesia was determined by testing eye reflexes and tail pinch. Then, animals were placed in the prone position in an incubator (MMS, Chelles, France) warmed to maintain a stable cutaneous temperature $\left(35.5^{\circ} \mathrm{C}\right)$. Skin blood flow, systolic arterial blood pressure (ABP), and skin temperature were recorded by a data acquisition system (Biopac, Santa Barbara, CA, USA) at the sample frequency of $200 \mathrm{~Hz}$ and analyzed off-line by software (AcqKnowledge, Biopac). Local cutaneous temperature on the hind limb was measured using a surface type-T thermocouple probe close to the site for skin blood flow measurements. The thermocouple was connected to an electronic thermometer (BAT12; Physitemp Instruments Inc, Clifton, NJ, USA). Systolic ABP was measured non-invasively using an XBP 1000 (Kent Scientific, Torrington, CT, USA) positioned on the tail. Data collection began with a 1-minute basal period before the onset of local pressure application or current application for iontophoretic deliveries and was continuously recorded for 20 minutes. All animals were killed at the end of the experiment by an overdose of anesthetic agent.

\subsubsection{Assessment of cutaneous neurovascular function (PIV)}

Cutaneous blood flow was measured by laser Doppler flowmetry (LDF) using a weighbridge that was adapted to hold a laser Doppler probe at one end (PF408, Periflux; Perimed, Jarfalla, Sweden). This method was described by Fromy et al. [11]. The weighbridge was equilibrated carefully with the probe placed in the middle of the hairless part of the hind limb, at a distance from the nerve lesion but still on the cutaneous area innervated by the sciatic nerve, and an external pressure was progressively increased at $11.1 \mathrm{~Pa} / \mathrm{s}$, through the laser Doppler probe. The LDF signal was digitized with a 200-Hz sampling frequency using a computerized acquisition system (Biopac).

\subsubsection{Assessment of the endothelium-dependent and-independent responses}

Because ACh is the most widely used drug to assess the endothelial L-arginine/nitric oxide pathway, the endothelium-dependent vasodilation in the cutaneous microcirculation was provoked by the iontophoretic delivery of ACh (acetylcholine chloride, 2\%, Sigma-Aldrich) using anodal current for 20 seconds and $0.1 \mathrm{~mA}$. Because SNP is an exogenous nitric oxide donor, the endotheliumindependent vasodilation was provoked by the iontophoretic delivery of SNP (sodium nitroferricyanide (III) dehydrate, $2 \%$, Sigma-Aldrich) using cathodal current for 20 seconds and $0.1 \mathrm{~mA}$. The iontophoresis technique was chosen to assess in vivo the cutaneous microvascular function while avoiding any systemic effects. SNP and ACh were dissolved in deionized water. Cutaneous blood flow was measured at the centre of iontophoretic delivery over an area of 
$1.2 \mathrm{~cm}^{2}$ using a laser Doppler probe (481-1, Perimed) positioned in the middle of the hairless part of the hind limb, at a distance from the nerve lesion but still on the cutaneous area innervated by the sciatic nerve.

\subsubsection{Tail flick assessment}

Nociceptive thermal thresholds were measured by the tail flick method as previously described [34,35]. Acute noxious thermal test was performed on the tail to evaluate any nerve changes upstream from the sciatic nerve compression that could influence DRG neurons and neuropeptides. The conscious rats were maintained in a restrainer and placed on the surface of the tail-flick analgesia meter (Apelex model DS 20, Socrel, Bagneux, France). Animals were placed in clear Plexiglas boxes and a limited portion of the tail $(2-3 \mathrm{~cm}$ from the tip of the tail) was exposed to radiant heat $\left(1.3^{\circ} \mathrm{C} / \mathrm{s}\right)$. A cutoff time of 11 seconds was imposed to prevent tissue damage. Five measurements of the tail withdrawal latency were taken and averaged for each rat.

\subsubsection{Von Frey assessment}

The mechanical threshold for hind paw withdrawal was determined using an electronic Von Frey anesthesiometer (Almemo 2390-5 Ahlborn, IITC Inc, Woodland Hill, CA, USA). Rats were placed in clear Plexiglas boxes on an elevated mesh screen. Mechanical pressure (Bioseb, Chaville, France) was applied to the plantar surface of the right hind paw in a series of ascending forces using a rigid blunt tip. Five measurements of the mechanical threshold were taken and averaged for each rat.

\subsubsection{Tissue preparation for light microscopy to confirm CNC model}

Sciatic nerve segments from the compression area in each animal were harvested. The segments were fixed in $2.5 \%$ glutaraldehyde in $0.1 \mathrm{M}$ phosphate buffer solution at $10^{\circ} \mathrm{C}$ for 3 hours. Following initial fixation in glutaraldehyde, specimens were then postfixed in $1 \%$ osmium tetroxide in $0.1 \mathrm{M}$ phosphate buffer solution, dehydrated, and embedded in Epon resin (Miller-Stephenson, Sylmar, CA, USA). Semi-thin sections were prepared at $0.5-\mu \mathrm{m}$ thickness and stained with toluidine blue, and micrographs were taken with an Olympus Provis AX70 microscope (Olympus Optical Co Ltd, Tokyo, Japan). At the histological level, our results (Fig. 1) show that 1 - and 6-month CNC led to a decrease in myelin thickness in axonal density and diameter. Similar features were previously reported $[19,20]$, supporting the efficacy of the applied nerve compression used in the present study.

\subsection{Data analysis}

The LDF signal was averaged every 10 seconds to reduce the instantaneous variability of the signal as a result of vasomotion. All vasodilator responses to local pressure application and to iontophoretic deliveries of SNP and ACh are reported as the maximal percent increase from their respective baseline values. Data are expressed as the means \pm SEM. One-way analysis of variance was followed by the Student-Bonferroni multiple-range test to estimate the significance of differences between groups. Student's paired $t$-test was used to evaluate the significance of changes within a group. A 2-tailed $P$ value $<0.05$ was regarded as statistically significant.

\section{Results}

For all protocols, there was no variation in systolic ABP and skin temperature within each group throughout the experiment (Table 1). Moreover, basal values of systolic ABP, skin blood flow, and skin temperature were not different between groups (Table 1).

\subsection{CNC reduced or abolished cutaneous PIV according to CNC duration}

To evaluate the effects of local CNC on the surrounding tissue, we studied the cutaneous neurovascular interaction through PIV assessment.

In the control $\mathrm{C} 1$ group, the skin blood flow increased from baseline (59 \pm 8 arbitrary unit (a.u.)) to a maximal value (102 \pm 14 a.u., $P<0.001)$ in response to local pressure application, representing a PIV of $74 \% \pm 7 \%$ from baseline (Fig. $2 \mathrm{~A}$ ). In the $\mathrm{C} 1$ group, the skin blood flow increased from baseline ( $55 \pm 6$ a.u.) to a maximal value $(69 \pm 5$ a.u., $P<0.01)$ in response to local pressure application, representing a PIV of $25 \% \pm 8 \%$ that was reduced compared to the control C1 group $(P<0.001)$ (Fig. $2 A)$. Thus, short-term $\mathrm{CNC}$ resulted in a reduction in cutaneous PIV. In contrast, PIV was not reduced on a cutaneous area not innervated by nerve injury (the side contralateral to the $\mathrm{CNC}$ ) in short-term $\mathrm{CNC}$ rats (data not shown). These observations also suggest that in our experimental conditions, $\mathrm{CNC}$ did not activate nociceptive inputs to trigger the nociceptive signaling pathway to abolish PIV in healthy rats [13]. Thus, PIV reduction on a cutaneous area innervated by injured nerve was due to direct effect of the compression rather than nociceptive mechanisms.
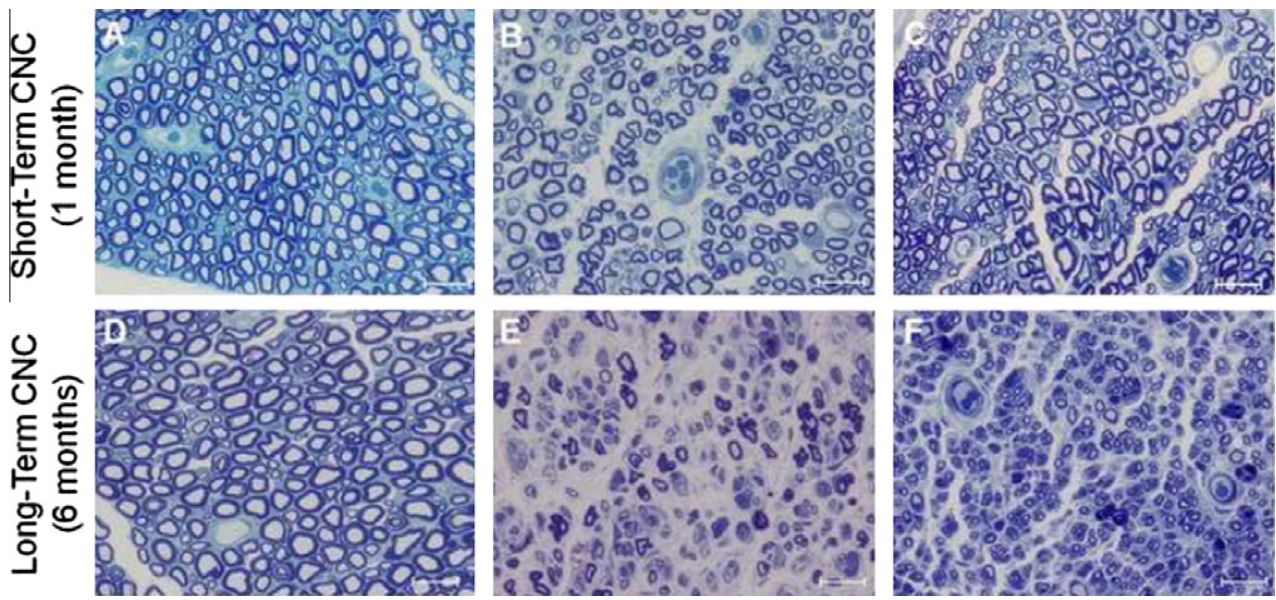

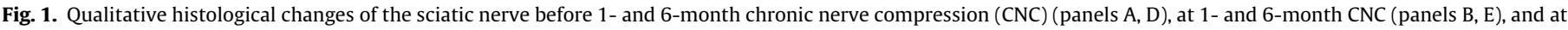

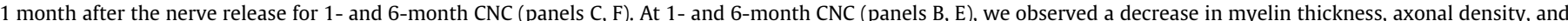

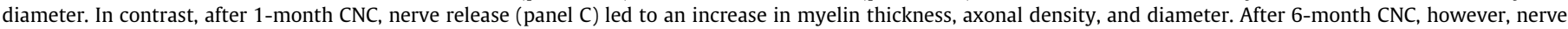
release (panel F) mainly only increased axonal density of small myelinated fibers. 
Table 1

Characteristics of short-term and long-term chronic nerve compression (CNC) groups.

\begin{tabular}{|c|c|c|c|c|}
\hline Groups & Body weight (g) & Systolic ABP (mm Hg) & Cutaneous temperature $\left({ }^{\circ} \mathrm{C}\right)$ & Basal LDF (a.u.) \\
\hline \multicolumn{5}{|c|}{ Short-term CNC } \\
\hline Control C1 & $365 \pm 13$ & $104 \pm 8$ & $35.6 \pm 0.1$ & $59 \pm 8$ \\
\hline $\mathrm{C} 1$ & $372 \pm 5$ & $110 \pm 4$ & $35.6 \pm 0.1$ & $55 \pm 6$ \\
\hline $\mathrm{R} 1 \mathrm{C} 1$ & $436 \pm 12$ & $97 \pm 6$ & $35.7 \pm 0.1$ & $60 \pm 4$ \\
\hline \multicolumn{5}{|c|}{ Long-term $\mathrm{CNC}$} \\
\hline Control C6 & $714 \pm 24^{* * *}$ & $99 \pm 4$ & $35.7 \pm 0.1$ & $54 \pm 4$ \\
\hline C6 & $722 \pm 18^{* * * *}$ & $109 \pm 6$ & $35.6 \pm 0.1$ & $63 \pm 8$ \\
\hline R1C6 & $683 \pm 23^{* * * *}$ & $101 \pm 6$ & $35.5 \pm 0.1$ & $55 \pm 6$ \\
\hline
\end{tabular}

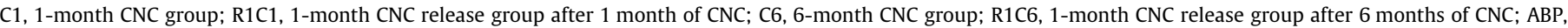
arterial blood pressure; LDF, laser Doppler flow.

Data are presented as means \pm SEM; $n=10$ in each group.

${ }^{* * *} P<0.001$ vs their respective short-term CNC groups.
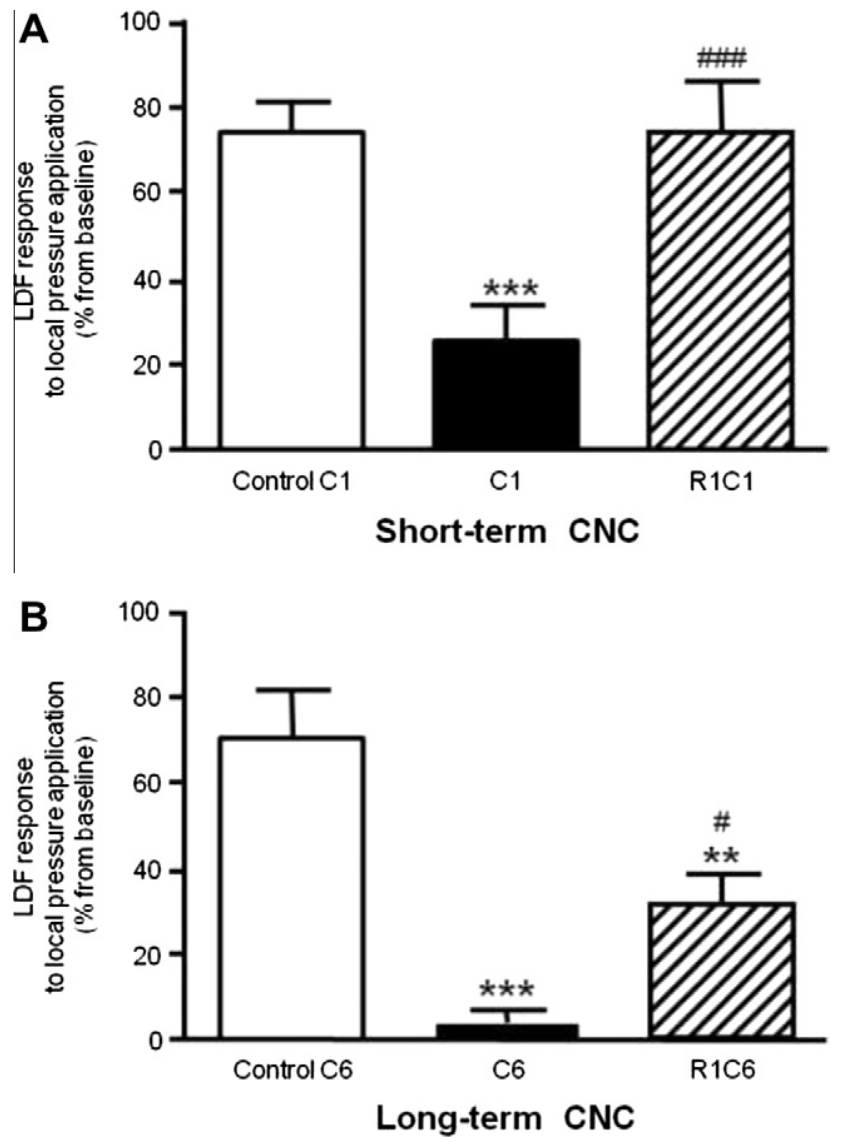

Fig. 2. Percent increase in cutaneous laser Doppler blood flow (LDF) from baseline in response to local pressure application in short-term (panel A) and long-term (panel B) chronic nerve compression (CNC) and at 1 month after the nerve release. C1, 1-month CNC group; R1C1, 1-month CNC release group after 1 month of CNC; C6, 6-month CNC group; R1C6, 1-month CNC release group after 6 months of CNC. Data are presented as means $\pm \mathrm{SEM} ; \mathrm{n}=10$ in each group. ${ }^{* *} P<0.01 ;{ }^{* * *} P<0.001$ vs control C1 in panel A and control C6 in panel B; ${ }^{\# \# \# P<0.001 ; ~}{ }^{\#} P<0.05$ vs $C 1$ in panel A and $\mathrm{C} 6$ in panel $\mathrm{B}$.

In the R1C1 group, skin blood flow increased from baseline (60 \pm 4 a.u.) to a maximal value ( $104 \pm 11$ a.u., $P<0.001$ ) (Fig. $2 \mathrm{~A}$ ) in response to local pressure application, representing a PIV of $74 \% \pm 12 \%$ that was no longer different from control $\mathrm{C} 1$, showing a full recovery of cutaneous PIV at 1 month after nerve release in short-term CNC conditions.

In the control $\mathrm{C} 6$ group, skin blood flow increased from baseline (54 \pm 4 a.u.) to a maximal value $(92 \pm 6$ a.u., $P<0.001)$ in response to local pressure application, representing a PIV of $70 \% \pm 11 \%$
(Fig. 2B) in long-term CNC. In contrast, in the C6 group, the skin blood flow did not increase from baseline ( $63 \pm 8$ a.u.) in response to local pressure application, showing that long-term CNC totally abolished the cutaneous PIV. In contrast, PIV was preserved on the side contralateral to the CNC (data not shown), showing that the abolition of PIV during long-term CNC was a direct consequence of $\mathrm{CNC}$, not a consequence of altered nociception, as mentioned above in short-term CNC.

In the R1C6 group, the local pressure application increased skin blood flow from baseline $(51 \pm 4$ a.u.) to a maximal value (67 \pm 7 a.u. $P<0.01$ ) (Fig. 2 B), representing a PIV of $31 \% \pm 7 \%$ that was reduced compared to the control C6 group $(P<0.01)$, but significantly increased compared to the C6 group, who showed no PIV $(P<0.05)$. This result shows a partial recovery of cutaneous PIV at 1 month after nerve release in long-term CNC conditions.

\subsection{Neuropeptide contribution differs in PIV in short-term CNC}

In capsaicin-sensitive nerve fibers [31,33], the potent vasodilator neuropeptides CGRP and pituitary adenylate cyclase activating polypeptide (PACAP) coexist and are in various organs, including the skin $[7,54,56,58]$. Since we previously reported their involvement in PIV in physiological conditions $[9,12]$, we hypothesized that PIV reduction observed in the $\mathrm{C} 1$ group could be due to a reduction in CGRP and/or PACAP in cutaneous nerve endings. This hypothesis was tested by a pharmacological approach.

Before CNC, PIV was totally abolished following injection of the CGRP antagonist CGRP8-37, while it was reduced by $76 \%$ following injection of the VPAC antagonist SC923 compared to the untreated control C1 group (Table 2). The remaining PIV under VPAC1/VPAC2 blockade was totally abolished under the dual blockade (CGRP8$37+$ SC923 $)(P<0.05)$ (Table 2). This indicates that CGRP has a greater contribution than VIP/PACAP in PIV in healthy conditions.

In short-term CNC, the reduced PIV in the untreated C1 group was totally abolished following CGRP8-37, SC923, and CGRP8$37+$ SC923 injections (Table 2), showing comparable contributions of CGRP, VIP/PACAP in the reduced PIV in short-term CNC, suggesting neuropeptide reorganization as reported in CNC [25,38,60,61].

At 1 month after the nerve release (R1C1 group), the recovered PIV in the untreated R1C1 group was totally abolished following injections of CGRP8-37 and CGRP8-37 + SC923, while it was decreased by $78 \%$ following SC923 injection (Table 2 ). This indicates that the recovered PIV relies mainly on CGRP rather than VPAC1/ VPAC2, as in the healthy control condition described above.

\subsection{Key role of small fiber function in PIV recovery after nerve release}

To distinguish the small from the large nerve fiber function, we tested the nociceptive thermal sensitivity and the low mechanical sensitivity. 
Table 2

Effects of pharmacological blockers on the maximal increase in skin blood flow in response to local pressure application in short-term chronic nerve compression (CNC).

\begin{tabular}{|c|c|c|c|c|}
\hline \multirow[t]{2}{*}{ Groups } & \multicolumn{4}{|c|}{ Increase in skin blood flow to local pressure application (\% from baseline) } \\
\hline & Untreated & CGRP8-37 & SC923 & CGRP8-37 + SC923 \\
\hline Control C1 & $74 \pm 7$ & $7 \pm 4^{* * * *}$ & $18 \pm 3^{* * * * \#}$ & $3 \pm 3^{* * *}$ \\
\hline $\mathrm{C} 1$ & $25 \pm 8$ & $1 \pm 4^{*}$ & $5 \pm 4^{*}$ & $6 \pm 2^{*}$ \\
\hline $\mathrm{R} 1 \mathrm{C} 1$ & $74 \pm 12$ & $10 \pm 3^{* * *}$ & $16 \pm 4^{* * *}$ & $5 \pm 2^{* * *}$ \\
\hline
\end{tabular}

C1, 1-month CNC group; R1C1, 1-month CNC release group after 1 month of CNC; C6, 6-month CNC; R1C6, 1-month CNC release group after 6 months of CNC. Data are presented as means $\pm S E M ; n=10$ in each group.

$P<0.05$ vs respective untreated group.

** $P<0.001$ vs respective untreated group.

\# $P<0.05$ vs CGRP8-37 + SC923.

\subsubsection{Tail flick responses}

Sensitivity to low-rate noxious heat is primarily mediated by $\mathrm{C}$ fiber, although A $\delta$ fiber can also be activated [59]. Overall, the nerve response mainly reflects small nerve fibers thinly or not myelinated. The tail flick latency was increased in short-term CNC (control C1: $5.4 \pm 0.1$ seconds; C1: $6.3 \pm 0.2$ seconds; $P<0.001$; Fig. $3 \mathrm{~A}$ ) and long-term CNC (control C6: $8.7 \pm 0.2 \mathrm{sec}-$ onds; C6: $9.3 \pm 0.2$ seconds; $P<0.001$; Fig. $3 B$ ), showing a hypoalgesic response to thermal stimulus due to small nerve fiber dysfunction in both short- and long-term CNC.

At 1 month after the nerve release following short-term CNC (R1C1 group), the tail flick latency ( $5.7 \pm 0.1$ seconds) was not different compared to the control $\mathrm{C} 1$ group (Fig. 3A), indicating a complete recovery of small nerve fiber function. In contrast, 1 month after the nerve release following long-term CNC (R1C6 group), the tail flick latency was decreased compared to the control C6 group ( $7.7 \pm 0.2$ seconds; $P<0.001$; Fig. $3 \mathrm{~B})$, showing a thermal hyperalgesia. Since this hyperalgesia may reflect nerve regeneration, these data suggest that the recovery of small nerve fibers was in progress. It is possible that small nerve fibers would require more time to fully recover from long-term CNC compared to shortterm CNC.

\subsubsection{Von Frey responses}

Sensitivity to light touch is primarily associated to large myelinated $A \beta$ fibers [49]. The paw withdrawal threshold was increased (control C1: $20.2 \pm 0.2 \mathrm{~g} ; \mathrm{C} 1: 23.3 \pm 0.5 \mathrm{~g} ; P<0.001$ ) in short-term CNC (Fig. 3C) and long-term CNC (control C6: $22.2 \pm 0.1 \mathrm{~g}$; C6: $23.4 \pm 0.1 \mathrm{~g} ; P<0.001$; Fig. 3D), indicating large nerve fiber dysfunction. At 1 month after the nerve release, the paw withdrawal threshold remained increased in the R1C1 $(21.9 \pm 0.1 \mathrm{~g} ; P<0.001)$ and R1C6 $(22.5 \pm 0.1 \mathrm{~g} ; P<0.05)$ groups compared to their respective controls (Fig. 3C and D), showing that large fiber function was still impaired. It is interesting to underline that nociceptive thermal and low mechanical thresholds were increased in the control C6 group compared to the control C1 group. This may be related to the influence of increased body weight (Table 1) on thermal and mechanical sensitivities, as previously reported $[28,39]$.
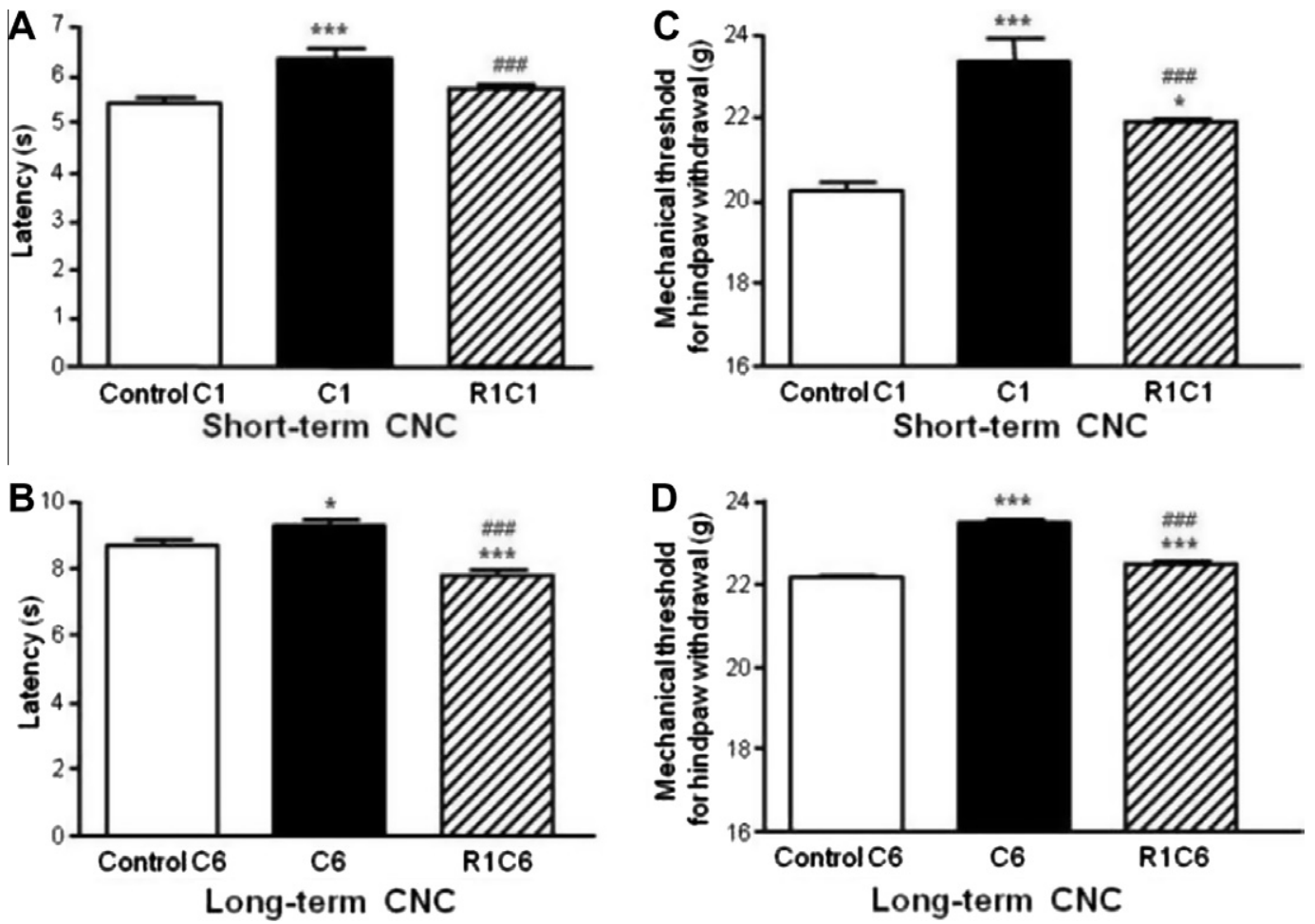

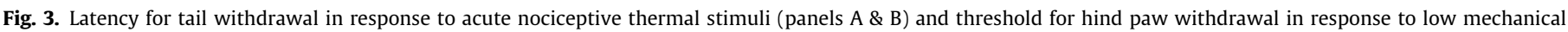

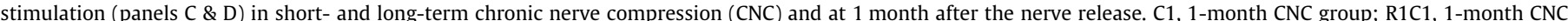

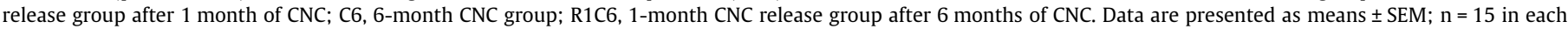
group. ${ }^{*} P<0.05$; ${ }^{* * *} P<0.001$ vs control $C 1$ in panels A \& $C$ and control C6 in panels B \& D; ${ }^{\# \# \#<~} 0.001$ vs $C 1$ in panels A \& $C$ and C6 in panels B \& D. 


\subsection{Abnormal endothelial response occurred in long-term CNC}

To discriminate vascular changes from neurovascular changes occurring in the cutaneous area innervated by the injured nerve, we tested two cutaneous microvascular functions.

The endothelium-independent vasodilator responses to iontophoretic delivery of SNP were not different between short-term CNC groups (control C1: $87 \% \pm 10 \%, \mathrm{C} 1$ : $74 \% \pm 13 \%$, and $\mathrm{R} 1 \mathrm{C} 1$ : $79 \% \pm 12 \%$ ) and between long-term CNC groups (control C6: $91 \% \pm 8 \%$, C6: $74 \% \pm 12 \%$, and R1C6: $87 \% \pm 7 \%$ ). Thus, the vascular smooth muscle function was preserved in short- and long-term CNC.

In short-term $\mathrm{CNC}$, endothelium-dependent responses to iontophoretic delivery of ACh were not different between groups (control C1: $56 \% \pm 9 \%, \mathrm{C} 1: 56 \% \pm 12 \%$, and R1C1: $56 \% \pm 5 \%$ [Fig. $4 \mathrm{~A}$ ]), indicating that the endothelial function was preserved in shortterm CNC. In contrast, in long-term CNC, the ACh-mediated vasodilation was enhanced $(108 \% \pm 12 \%)$ in the $\mathrm{C} 6$ group compared to the control C6 $(60 \% \pm 2 \%, P<0.01)$ and R1C6 $(42 \% \pm 8 \%, P<0.001)$ groups (Fig. 4B), indicating an altered endothelial function, since vascular smooth muscle function was intact. To further elucidate this enhanced endothelial response, we used aspirin to inhibit COX pathway. ACh-mediated vasodilation was unchanged by aspirin in the control C6 and R1C6 groups, showing that COX-derived prostaglandins play no or a minor role in ACh-mediated vasodilation, as previously reported in physiological conditions $[15,26,27,37]$. In contrast, the enhanced vasodilation in the C6 group was blocked $(44 \% \pm 11 \%)$ by aspirin and was not different from the control C6 and R1C6 groups any more (Fig. 4C), suggesting that prostaglandins could contribute to the altered endothelial function in long-term CNC.

\section{Discussion}

In the present study, we evaluated the severity of CNC by using functional exploration of the cutaneous neurovascular interaction in an area innervated by the compressed nerve using pressure-induced vasodilation and other assessments of microvascular function. We report that in short-term $\mathrm{CNC}$, the cutaneous neurovascular interaction was impaired and associated with small nociceptive fiber dysfunction, likely through changes in neuropeptide contribution but without any apparent impairment of vascular smooth muscle response to nitric oxide. Long-term CNC totally disrupted PIV, and was associated with nerve dysfunction and abnormal endothelial function. Nerve release restored small nerve fiber function prior to large nerve fiber function, even though the time required to fully recover depended on the lesion severity.

We observed that short-term CNC reduced PIV by $66 \%$ and increased nociceptive thermal latency by $17 \%$ and low mechanical threshold by $18 \%$, meaning that both small and large nerve fibers were impaired. Similarly, small nerve fiber function was affected in chronic low-pressure nerve compression such as CTS [1], and increased nociceptive thermal latency was previously reported at 1 month after CNC [40]. Since PIV relies on intact small nerve fiber function [10,12], we suggest that C-fiber alteration rather than large fiber alteration could be responsible for PIV reduction in short-term $\mathrm{CNC}$. Increased nociceptive latency to a thermal stimulus has been linked to a decrease in CGRP and substance P expression in the small nerve fibers at 1 month after CNC [40]. Additionally, a reorganization of the neurotransmitters was reported after nerve injury $[25,38,60,61]$. In sensory neurons, CGRP was decreased $[40,61]$, whereas PACAP expression increased in response to complete sciatic nerve transection $[25,60]$ or to 1 -month CNC [38]. Our present pharmacological experiments indicated that the CGRP contribution to PIV was greater in physiological conditions (control C1) than in short-term $\mathrm{CNC}(\mathrm{C} 1)$, consistent with the above reports regarding
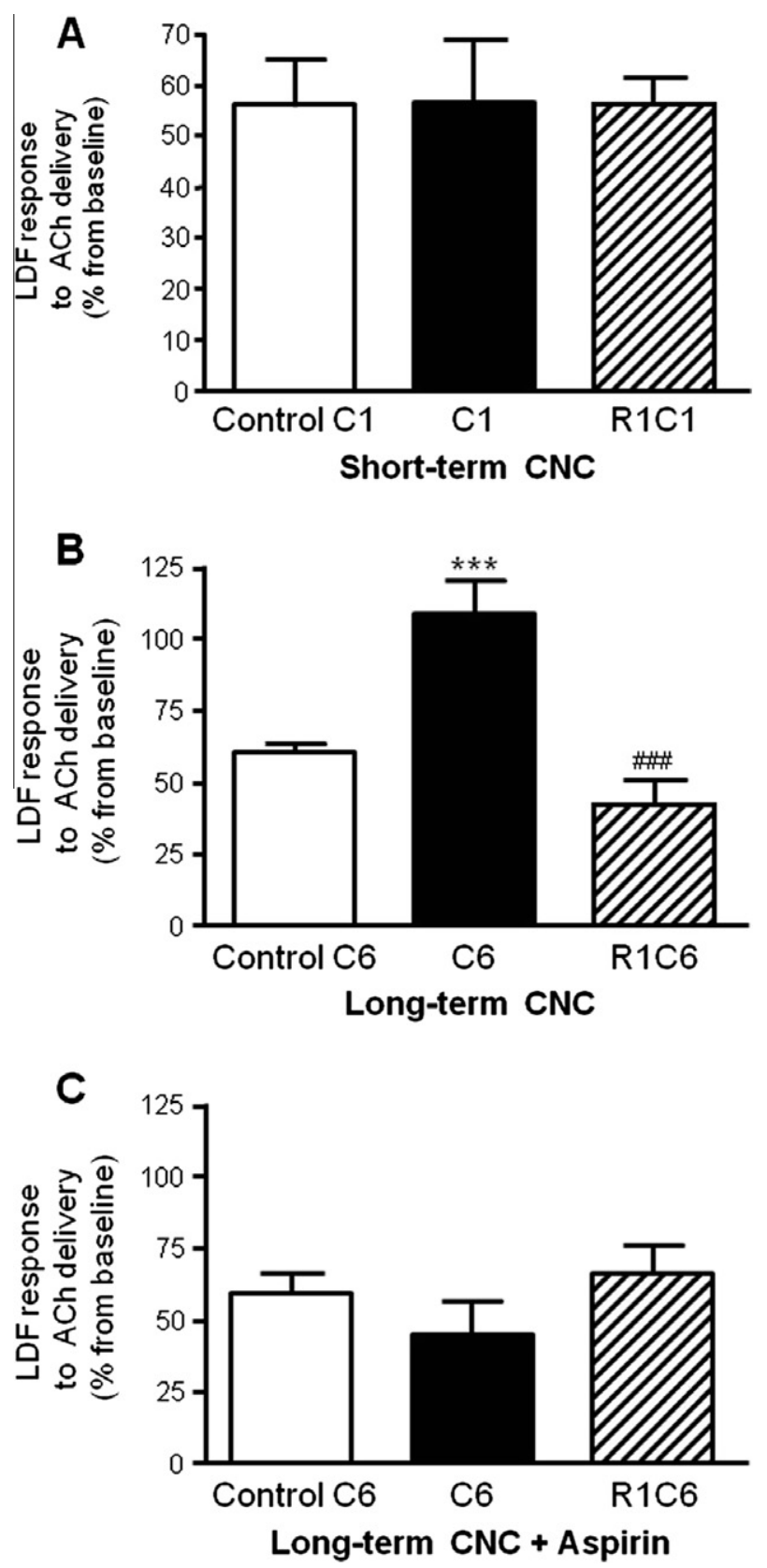

Fig. 4. Percent increase in cutaneous laser Doppler blood flow (LDF) from baseline in response to iontophoretic delivery of acetylcholine (ACh) in short- and long-term chronic nerve compression (CNC) and at 1 month after the nerve release (panels A \& $B$ ). Effects of cyclooxygenase (COX) inhibition using aspirin on percent increase in cutaneous LDF from baseline in response to iontophoretic delivery of ACh in longterm CNC and at 1 month after the nerve release (panel C). C1, 1-month CNC group; R1C1, 1-month CNC release group after 1 month of CNC; C6, 6-month CNC group; R1C6, 1-month CNC release group after 6 months of CNC. Data are presented as means $\pm \mathrm{SEM} ; \mathrm{n}=10$ in each group. ${ }^{* * *} P<0.001$ vs control C6; ${ }^{\# \# \#} P<0.001$ vs C6.

neuropeptide reorganization after nerve injury. In addition to nervous function, PIV requires intact endothelial function $[5,12,44]$, and since ACh-mediated vasodilation was unchanged in short-term $\mathrm{CNC}$, the reduction in PIV may not be explained by endothelial dysfunction. Overall, our results suggest that PIV is reduced through small fiber dysfunction and changes in neuropeptide function in short-term CNC. This further suggests that local nerve injury disturbs the surrounding tissue and could be detected by a neurovascular test on a cutaneous area innervated by the injured nerve. 
At 1 month after the nerve release in short-term $\mathrm{CNC}$, cutaneous PIV and the nociceptive thermal threshold were fully recovered, whereas the low mechanical threshold was not. This represents further evidence for the close relationship between PIV and small nerve fiber function, although PIV is also associated with altered large fiber function as previously reported in diabetes [6]. Regarding the large nerve fibers, axonal sprouting is considered to be a reactive response to the loss of myelin barrier, and the number of myelinated fibers returned to normal values after 1 month of nerve recovery [2], but these regenerated fibers can be altered in their original function [19]. This could explain the partial recovery of the low mechanical threshold observed in this study. In shortterm CNC, nerve release could thus restore the small nerve fiber function (PIV and nociceptive thermal threshold) more rapidly than the large nerve fiber function. It is worth noting that 2 weeks after nerve release, PIV was already restored, while small nerve fiber function was still impaired (unpublished observations). Together, these findings suggest that evaluation of small nerve fiber function, particularly via a noninvasive assessment such as PIV, could provide helpful information regarding the recovery of the tissue at the periphery of the nerve injury.

Increasing the duration of the CNC led to complete blockade of PIV, and was associated with increased nociceptive thermal (7\%) and low mechanical thresholds (6\%) compared to the control C6 group. During severe nerve injury, CGRP may be upregulated locally at the nerve injury site to promote small nerve fiber regeneration $[18,29,36,50]$. A reorganization of nerve fibers from myelinated fibers to slightly myelinated or unmyelinated fibers has also been reported as a direct consequence of $\mathrm{CNC}[4,18,40]$. Based on our present data, we suggest that nerve regeneration and fiber size redistribution could have occurred after long-term $\mathrm{CNC}$, preventing a further increase in nociceptive thermal and low mechanical thresholds. However, in long-term CNC, PIV was totally abolished, suggesting no beneficial effect from any potential nerve reorganization. Some other mechanisms could have taken place that prevented a subsequent PIV improvement. Indeed, neuropeptides are conveyed within nerve fibers by axonal transport from the DRG neurons to nerve terminals. However, during severe nerve injury, axonal transport has been reported to be blocked [41], affecting the functional and structural integrity of both proximal and distal parts of the axon. Changes in the proximal part of the axon will affect DRG neurons that synthesize neuropeptides [61], and changes in the distal part of the axon will affect target cells, for example, the skin tissue. Thus, blockade of the axonal transport could have prevented CGRP migration [8] to the peripheral cutaneous tissue and could have contributed to the inhibition of PIV in the long-term CNC group.

Since nociceptive thermal and low mechanical thresholds were not impaired as much as PIV in long-term CNC, assessment of neurovascular interaction using PIV appears to be a particularly sensitive tool to evaluate the severity of longer-term nerve compression.

Regarding cutaneous vascular function in long-term CNC, our present results showed an enhanced ACh-mediated vasodilation that was reversed by COX inhibition, indicating an increased participation of prostaglandins compared to physiological conditions when they play no [15,32] or only a minor role [26]. A possible explanation may be related to an increase in COX2-IR macrophage cell profiles observed within a region of the ipsilateral sciatic nerve adjacent to the injury site 1 month after partial ligation [30]. During long-term $\mathrm{CNC}$, macrophages are recruited at the nerve level [17] to remove axonal debris, clearing the path for axonal regeneration [43]. Macrophages were most abundant in compressed and distal areas of more pronounced damage than in proximal sections [19]. In the present study, the short distance between the site of the nerve compression and the site of the cutaneous measurements could suggest that the latter was affected by macrophages recruited by the nerve lesion. Interestingly, macrophages express al- pha-7 nicotinic ACh receptors $[21,55]$ and in the presence of ACh, macrophages release COX-2-dependent prostaglandin E2, a potent vasodilatory factor. In addition, COX1-IR has been observed in bone-marrow-derived macrophages in the epidermis of the footpad 1 month after partial ligation [30]. When stimulated, over-produced prostaglandins probably activate and sensitize the microvascular smooth muscle cells, and may have led to the larger-than-normal vasodilator responses we observed. Since the CNC model used in the present study is less traumatic to tissue than partial ligation, it could explain why the larger vasodilator response to ACh was observed later than in Ma and Eisenach's study [30]. Therefore, besides endothelial cells, we cannot rule out the possible involvement of other cells such as macrophages in the enhanced response to ACh iontophoresis on the cutaneous environment distal to the nerve lesion. Whether these underlying mechanisms could participate in PIV reduction remains to be determined.

At 1 month after the nerve release in long-term $\mathrm{CNC}$, the cutaneous PIV and the low mechanical threshold were partially recovered, whereas the nociceptive thermal threshold was decreased, indicating thermal hyperalgesia. The partial recovery of the low mechanical threshold indicates large fiber remyelination that is unlikely to be involved in partial recovery of PIV, which relies on unmyelinated fibers [6]. Thermal hyperalgesia was previously observed in situations of nerve regeneration and re-innervation [3], or during insufficient upregulation of neuropeptide $Y$, which has antinociceptive effects in the rat spinal cord in chronic constriction injury $[40,42,47]$. This small nerve fiber dysfunction with a possible improvement of anterograde CGRP axonal transport due to nerve release could contribute to the partial recovery of PIV. In contrast, the ACh-mediated vasodilation was back to normal, showing an intact endothelial function. This is also consistent with the idea that recovery of PIV was limited by the remaining small nerve fiber dysfunction. Our findings support the idea that the time needed to fully recover neurovascular interactions after nerve release is related to the duration of nerve compression.

In summary, we provide evidence in the present report that local nerve injury causes damage to the surrounding tissue that can be detected noninvasively by a cutaneous neurovascular test on the skin innervated by the injured sciatic nerve. We report that PIV appears sensitive to functional and structural nerve fiber changes regarding the shift between small and large fibers, neuropeptide contribution, and axonal transport alteration. We also found that longer-duration CNC was associated with less neurovascular recovery. We therefore conclude that PIV can be used as a noninvasive tool to evaluate the severity of the complications of $\mathrm{CNC}$, as well as the progress of tissue recovery.

Assessing the cutaneous neurovascular interaction could help to detect neuropathies occurring during carpal tunnel syndrome and could evaluate the nervous function recovery, avoiding relapses.

\section{Conflict of interest statement}

No author has any conflict of interest related to the content of this paper.

\section{Acknowledgements}

This study was funded by Agence Nationale de la Recherche grant ANR-07-SEST-01601. J. Pelletier was supported by a grant from the French Ministère de l'enseignement supérieur et de la recherche (EDISS). We thank Mr Gregory James for technical support.

\section{References}

[1] Arendt-Nielsen L, Gregersen H, Toft E, Bjerring P. Involvement of thin afferents in carpal tunnel syndrome: evaluated quantitatively by argon laser stimulation. Muscle Nerve 1991;14:508-14 
[2] Bruna J, Udina E, Ale A, Vilches JJ, Vynckier A, Monbaliu J, Silverman L, Navarro $X$. Neurophysiological, histological and immunohistochemical characterization of bortezomib-induced neuropathy in mice. Exp Neurol 2010;223:599-608.

[3] Casals-Diaz L, Vivo M, Navarro X. Nociceptive responses and spinal plastic changes of afferent C-fibers in three neuropathic pain models induced by sciatic nerve injury in the rat. Exp Neurol 2009;217:84-95.

[4] Chao T, Pham K, Steward O, Gupta R. Chronic nerve compression injury induces a phenotypic switch of neurons within the dorsal root ganglia. J Comp Neurol 2008;506:180-93.

[5] Demiot C, Fromy B, Saumet JL, Sigaudo-Roussel D. Preservation of pressureinduced cutaneous vasodilation by limiting oxidative stress in short-term diabetic mice. Cardiovasc Res 2006;69:245-52.

[6] Demiot C, Tartas M, Fromy B, Abraham P, Saumet JL, Sigaudo-Roussel D. Aldose reductase pathway inhibition improved vascular and C-fiber functions, allowing for pressure-induced vasodilation restoration during severe diabetic neuropathy. Diabetes 2006;55:1478-83.

[7] Dorner GT, Wolzt M, Eichler HG, Schmetterer L. Effect of pituitary adenylate cyclase activating polypeptide 1-27 on ocular, cerebral and skin blood flow in humans. Naunyn Schmiedebergs Arch Pharmacol 1998;358:657-62.

[8] Dumoulin FL, Raivich G, Haas CA, Lazar P, Reddington M, Streit WJ, Kreutzberg GW. Calcitonin gene-related peptide and peripheral nerve regeneration. Ann N Y Acad Sci 1992;657:351-60.

[9] Fizanne L, Sigaudo-Roussel D, Saumet JL, Fromy B. Evidence for the involvement of VPAC1 and VPAC2 receptors in pressure-induced vasodilatation in rodents. J Physiol 2004;554:519-528.

[10] Fromy B, Abraham P, Saumet JL. Non-nociceptive capsaicin-sensitive nerve terminal stimulation allows for an original vasodilatory reflex in the human skin. Brain Res 1998;811:166-8.

[11] Fromy B, Abraham P, Saumet JL. Progressive calibrated pressure device to measure cutaneous blood flow changes to external pressure strain. Brain Res Protocols 2000;5:198-203.

[12] Fromy B, Merzeau S, Abraham P, Saumet JL. Mechanisms of the cutaneous vasodilator response to local external pressure application in rats: involvement of CGRP, neurokinins, prostaglandins and NO. Br J Pharmacol 2000;131:1161-71.

[13] Fromy B, Sigaudo-Roussel D, Baron C, Roquelaure Y, Leftheriotis G, Saumet JL. Neuroendocrine pathway involvement in the loss of the cutaneous pressureinduced vasodilatation during acute pain in rats. J Physiol 2007;579:247-54.

[14] Garry A, Fromy B, Blondeau N, Henrion D, Brau F, Gounon P, Guy N, Heurteaux C, Lazdunski M, Saumet JL. Altered acetylcholine, bradykinin and cutaneous pressure-induced vasodilation in mice lacking the TREK1 potassium channel: the endothelial link. EMBO Rep 2007;8:354-9.

[15] Gohin S, Sigaudo-Roussel D, Conjard-Duplany A, Dubourg L, Saumet JL, Fromy B. What can current stimulation tell us about the vascular function of endogenous prostacyclin in healthy rat skin in vivo? J Invest Dermatol 2011;131:237-44.

[16] Gross AS, Louis DS, Carr KA, Weiss SA. Carpal tunnel syndrome: a clinicopathologic study. J Occup Environ Med 1995;37:437-41.

[17] Gupta R, Lin YM, Bui P, Chao T, Preston C, Mozaffar T. Macrophage recruitment follows the pattern of inducible nitric oxide synthase expression in a model for carpal tunnel syndrome. J Neurotrauma 2003;20:671-80.

[18] Gupta R, Rowshan K, Chao T, Mozaffar T, Steward O. Chronic nerve compression induces local demyelination and remyelination in a rat model of carpal tunnel syndrome. Exp Neurol 2004;187:500-8.

[19] Gupta R, Rummler L, Steward O. Understanding the biology of compressive neuropathies. Clin Orthop Relat Res 2005:251-60.

[20] Gupta R, Steward O. Chronic nerve compression induces concurrent apoptosis and proliferation of Schwann cells. J Comp Neurol 2003;461:174-86.

[21] Gurun MS, Parker R, Eisenach JC, Vincler M. The effect of peripherally administered CDP-choline in an acute inflammatory pain model: the role of alpha7 nicotinic acetylcholine receptor. Anesth Analg 2009;108:1680-7.

[22] Hammond DL, Ackerman L, Holdsworth R, Elzey B. Effects of spinal nerve ligation on immunohistochemically identified neurons in the L4 and L5 dorsal root ganglia of the rat. J Comp Neurol 2004;475:575-89.

[23] Jancso G, Santha P, Gecse K. Peripheral nerve lesion-induced uptake and transport of choleragenoid by capsaicin-sensitive c-fibre spinal ganglion neurons. Acta Biol Hung 2002;53:77-84.

[24] Jongsma H, Danielsen N, Sundler F, Kanje M. Alteration of PACAP distribution and PACAP receptor binding in the rat sensory nervous system following sciatic nerve transection. Brain Res 2000;853:186-96.

[25] Jongsma Wallin H, Danielsen N, Johnston JM, Gratto KA, Karchewski LA, Verge VM. Exogenous NT-3 and NGF differentially modulate PACAP expression in adult sensory neurons, suggesting distinct roles in injury and inflammation. Eur J NeuroSci 2001;14:267-82.

[26] Kellogg Jr DL, Zhao JL, Coey U, Green JV. Acetylcholine-induced vasodilation is mediated by nitric oxide and prostaglandins in human skin. J Appl Physiol 2005;98:629-32

[27] Khan F, Davidson NC, Littleford RC, Litchfield SJ, Struthers AD, Belch JJ. Cutaneous vascular responses to acetylcholine are mediated by a prostanoiddependent mechanism in man. Vasc Med 1997;2:82-6.

[28] Kriz N, Yamamotova A, Tobias J, Rokyta R. Tail-flick latency and self-mutilation following unilateral deafferentation in rats. Physiol Res 2006;55:213-20.

[29] Li XQ, Verge VM, Johnston JM, Zochodne DW. CGRP peptide and regenerating sensory axons. J Neuropathol Exp Neurol 2004;63:1092-103.
[30] Ma W, Eisenach JC. Morphological and pharmacological evidence for the role of peripheral prostaglandins in the pathogenesis of neuropathic pain. Eur NeuroSci 2002;15:1037-47.

[31] Moller K, Zhang YZ, Hakanson R, Luts A, Sjolund B, Uddman R, Sundler F. Pituitary adenylate cyclase activating peptide is a sensory neuropeptide: immunocytochemical and immunochemical evidence. Neuroscience 1993;57:725-32.

[32] Morris SJ, Shore AC. Skin blood flow responses to the iontophoresis of acetylcholine and sodium nitroprusside in man: possible mechanisms. J Physiol 1996;496:531-42.

[33] Mulder H, Uddman R, Moller K, Zhang YZ, Ekblad E, Alumets J, Sundler F. Pituitary adenylate cyclase activating polypeptide expression in sensory neurons. Neuroscience 1994;63:307-12.

[34] Nagy JI, Vincent SR, Staines WA, Fibiger HC, Reisine TD, Yamamura HI. Neurotoxic action of capsaicin on spinal substance $\mathrm{P}$ neurons. Brain Res 1980;186:435-44.

[35] Nakamura K, Kuntzman R, Maggio AC, Augulis V, Conney AH. Influence of 6hydroxydopamine on the effect of morphine on the tail-flick latency. Psychopharmacologia 1973;31:177-89.

[36] Neumann S, Doubell TP, Leslie T, Woolf CJ. Inflammatory pain hypersensitivity mediated by phenotypic switch in myelinated primary sensory neurons. Nature 1996;384:360-4.

[37] Noon JP, Walker BR, Hand MF, Webb DJ. Studies with iontophoretic administration of drugs to human dermal vessels in vivo: cholinergic vasodilatation is mediated by dilator prostanoids rather than nitric oxide. $\mathrm{Br}$ J Clin Pharmacol 1998;45:545-50.

[38] Pettersson LM, Dahlin LB, Danielsen N. Changes in expression of PACAP in rat sensory neurons in response to sciatic nerve compression. Eur J NeuroSc 2004;20:1838-48.

[39] Ramzan I, Wong BK, Corcoran GB. Pain sensitivity in dietary-induced obese rats. Physiol Behav 1993;54:433-5.

[40] Ruscheweyh R, Forsthuber L, Schoffnegger D, Sandkuhler J. Modification of classical neurochemical markers in identified primary afferent neurons with Abeta-, Adelta-, and C-fibers after chronic constriction injury in mice. J Comp Neurol 2007;502:325-36.

[41] Rydevik B, McLean WG, Sjostrand J, Lundborg G. Blockage of axonal transport induced by acute, graded compression of the rabbit vagus nerve. J Neurol Neurosurg Psychiatry 1980;43:690-8.

[42] Sapunar D, Modric-Jednacak K, Grkovic I, Michalkiewicz M, Hogan QH. Effect of peripheral axotomy on pain-related behavior and dorsal root ganglion neurons excitability in NPY transgenic rats. Brain Res 2005;1063:48-58.

[43] Sarikcioglu L, Yaba A, Tanriover G, Demirtop A, Demir N, Ozkan O. Effect of severe crush injury on axonal regeneration: a functional and ultrastructura study. J Reconstr Microsurg 2007;23:143-9.

[44] Sigaudo-Roussel D, Demiot C, Fromy B, Koitka A, Leftheriotis G, Abraham P Saumet JL. Early endothelial dysfunction severely impairs skin blood flow response to local pressure application in streptozotocin-induced diabetic mice. Diabetes 2004;53:1564-9.

[45] Sommer C, Galbraith JA, Heckman HM, Myers RR. Pathology of experimental compression neuropathy producing hyperesthesia. J Neuropathol Exp Neurol 1993;52:223-33.

[46] Svilpauskaite J, Truffert A, Vaiciene N, Magistris MR. Cutaneous silent period in carpal tunnel syndrome. Muscle Nerve 2006;33:487-93.

[47] Taiwo OB, Taylor BK. Antihyperalgesic effects of intrathecal neuropeptide $Y$ during inflammation are mediated by Y1 receptors. Pain 2002;96:353-63.

[48] Tanaka K, Zhang QL, Webster HD. Myelinated fiber regeneration after sciatic nerve crush: morphometric observations in young adult and aging mice and the effects of macrophage suppression and conditioning lesions. Exp Neurol 1992;118:53-61.

[49] Teliban A, Bartsch F, Struck M, Baron R, Janig W. Axonal thermosensitivity and mechanosensitivity of cutaneous afferent neurons. Eur J NeuroSci 2011;33:110-8.

[50] Toth CC, Willis D, Twiss JL, Walsh S, Martinez JA, Liu WQ, Midha R, Zochodne DW. Locally synthesized calcitonin gene-related peptide has a critical role in peripheral nerve regeneration. J Neuropathol Exp Neurol 2009;68:326-37.

[51] Truini A, Biasiotta A, La Cesa S, Di Stefano G, Galeotti F, Petrucci MT, Inghiller M, Cartoni C, Pergolini M, Cruccu G. Mechanisms of pain in distal symmetric polyneuropathy: a combined clinical and neurophysiological study. Pain 2010;150:516-21.

[52] Truini A, Galeotti F, Biasiotta A, Gabriele M, Inghilleri M, Petrucci MT, Cruccu G. Dissociation between cutaneous silent period and laser evoked potentials in assessing neuropathic pain. Muscle Nerve 2009;39:369-73.

[53] Truini A, Padua L, Biasiotta A, Caliandro P, Pazzaglia C, Galeotti F, Inghilleri M, Cruccu G. Differential involvement of A-delta and A-beta fibres in neuropathic pain related to carpal tunnel syndrome. Pain 2009;145:105-9.

[54] Wallengren J. Vasoactive peptides in the skin. J Investig Dermatol Symp Proc 1997;2:49-55.

[55] Wang H, Yu M, Ochani M, Amella CA, Tanovic M, Susarla S, Li JH, Wang H, Yang $\mathrm{H}$, Ulloa L, Al-Abed Y, Czura CJ, Tracey KJ. Nicotinic acetylcholine receptor alpha7 subunit is an essential regulator of inflammation. Nature 2003;421:384-8.

[56] Warren JB, Larkin SW, Coughlan M, Kajekar R, Williams T]. Pituitary adenylate cyclase activating polypeptide is a potent vasodilator and oedema potentiator in rabbit skin in vivo. Br J Pharmacol 1992;106:331-4. 
[57] Werner RA, Andary M. Carpal tunnel syndrome: pathophysiology and clinical neurophysiology. Clin Neurophysiol 2002;113:1373-81.

[58] Wilson AJ, Warren JB. Adenylate cyclase-mediated vascular responses of rabbit aorta, mesenteric artery and skin microcirculation. $\mathrm{Br} \mathrm{J}$ Pharmacol 1993;110:633-8.

[59] Yeomans DC, Proudfit HK. Nociceptive responses to high and low rates of noxious cutaneous heating are mediated by different nociceptors in the rat: electrophysiological evidence. Pain 1996;68:141-50.
[60] Zhang YZ, Hannibal J, Zhao Q, Moller K, Danielsen N, Fahrenkrug J, Sundler F. Pituitary adenylate cyclase activating peptide expression in the rat dorsal root ganglia: up-regulation after peripheral nerve injury. Neuroscience 1996;74:1099-110.

[61] Zheng LF, Wang R, Xu YZ, Yi XN, Zhang JW, Zeng ZC. Calcitonin gene-related peptide dynamics in rat dorsal root ganglia and spinal cord following different sciatic nerve injuries. Brain Res 2008;1187:20-32. 